\title{
Sobre el origen y significado de las lanzas utilizadas por la Guardia Real española
}

\author{
José Rivera Restrepo ${ }^{1}$
}

\author{
"Quilapán, Quilapán \\ el más grande Quilapán, \\ qué valiente Quilapán \\ mientras hayan coligües \\ tendremos lanzas Quilapán \\ para detener al español \\ Quilapán, Quilapán" \\ Canto guerrero tradicional mapuche ${ }^{2}$
}

En uno de los salones del Museo Histórico Militar de A Coruña, descubrí dos lanzas cruzadas, coronadas ambas con la bandera española. Similar imagen había tenido en Chile, hace un par de años: se trataba de análogas lanzas utilizadas por la Escolta Presidencial del Regimiento de Caballería Blindada N ${ }^{\circ} 1$ "Granaderos". Ellas, al parecer eran de madera de colihue. ${ }^{3}$ Luego, estando en Madrid, noté que similares lanzas eran utilizadas por los lanceros pertenecientes a la Guardia Real. El uniforme de los mismos está compuesto por una chaqueta ajustada y abrochada en el cuello, de color azul Cristina, pantalón del mismo color con una raya vertical roja, botas negras y casco con pelo de búfalo. En invierno van vestidos, además, con una capa azul Cristina. Conjuntamente, van armados con una lanza de madera de colihue, en cuya cúspide va izada la bandera española (Casa de S. M. El Rey, 2004). En este breve ensayo, pretendo establecer el verdadero origen y significado de dichas lanzas o picas.

\section{El temple araucano}

Las empresas de conquista española de la América, se encontraron con un digno rival, en el extremo del Cono Sur americano, en lo que actualmente

Chileno. Doctor en Derecho Civil por la Universidad Complutense de Madrid. Profesor de Derecho Civil, Universidad Gabriela Mistral, Chile. E-mail: jose.rivera@ugm.cl

Bengoa, 2000: 86-87.

3 El "colihue" (o coligüe, del mapuche coliu) es definido así: "Planta de la familia de las Gramíneas, cuyas cañas son rectas, de corteza lisa y muy resistente. Con ellas se hacían lanzas, y tienen hoy un cierto uso en la fabricación de muebles". Ver Real Academia Española (2001: 398). 
constituye el sur de Chile y de la Argentina: los mapuches ${ }^{4}$, conocidos por Alonso de Ercilla como "araucanos", ya que en sus territorios abundaban las lluvias (Faron, 1969). Así, "[l]os españoles bautizaron a esta región como Arauco ("agua fangosa")" 5 . Con todo, ellos se llamaban a sí mismos che ("pueblos") o mapuche ("pueblo de la tierra") (Bleiberg, 1968).

Los mapuches domesticaron la papa (patata) y la gallina, cultivaban, además, el maíz, la quínoa, las habichuelas, usando técnicas de regadío y terraplenes; eran personas valientes, jugaban chueca o palín, sumamente religiosos y abnegados. Siempre hicieron frente, gallardos, a los desastres naturales y a las invasiones extranjeras. Dicho temple forma parte del ADN de la población chilena ${ }^{6}$. Como reza el párrafo cuarto del Himno Nacional de Chile:

\section{"Si pretende el cañón extranjero \\ Nuestros pueblos osado invadir; \\ Desnudemos al punto el acero \\ Y sepamos vencer o morir. \\ Con su sangre el altivo araucano \\ Nos legó por herencia el valor; \\ Y no tiembla la espada en la mano \\ Defendiendo de Chile el honor".}

Es interesante la descripción que de los mapuches hace el polaco Ignacio Domeyko: "El indio, en tiempo de paz, es cuerdo, hospitalario, fiel en los tratos, reconocido a los beneficios, celoso del propio honor. Grave y muy formal en su trato, algo pensativo, severo, sabe respetar la autoridad, dispensando a cada cual el acatamiento y cariño que le corresponde" (Domeyko, 1971: 70). Respecto de los mapuches, Bleiberg acota lo siguiente: "Su fama es debida, sobre todo, a la heroica resistencia que hicieron a los españoles, a los que vencieron, por la táctica del ataque continuado" (Bleiberg, 1968: 313). Recordamos, en este punto, las palabras del español Alonso de Ercilla

4 Aún cuando, en honor a la verdad, en un mapa de la América Meridional, que data del 29 de agosto de 1671, aparece mencionado el territorio de "Chilli", desde el Pacífico hasta el Atlántico, al septentrión de la Tierra del Fuego y del Reino de la Patagonia (González García, 1995: 158).

5 Barella (1999) plantea que la voz "Arauco" proviene: "[d]e «ragh», greda; y «co», agua. Rauco (de «raghco»), agua gredosa". Olea Rosenbluth (2010) sugiere que "oficialmente, entre los ríos Itata y Toltén, en la gran región nombrada por muchos como «Araucanía», habitaba el pueblo mapuche".

$6 \quad$ En este sentido, Neruda acota lo siguiente: "Siempre recordaré los calcetines mojados junto al brasero y muchos zapatos echando vapor como pequeñas locomotoras. Luego venían las inundaciones, que se llevaban las poblaciones donde vivía la gente más pobre, junto al río. También la tierra se sacudía, temblores. Otras veces, en la cordillera asomaba un penacho de humo terrible: el volcán Laima despertaba". (Neruda, 1962: 24). 
y Zúñiga: "Chile, fértil provincia y señalada en la región antártica famosa, de remotas naciones respetada por fuerte, principal y poderosa; la gente que produce es tan granada, tan soberbia, gallarda y belicosa, que no ha sido por rey jamás regida ni a extranjero dominio sometida" (Ercilla y Zúñiga, 1991: 128-129). Los araucanos, singular pueblo, se mantuvieron independientes de la Corona Española por más de 260 años y nunca fueron conquistados por aquella. En este sentido, el español Navarro señala que: "Así pues, en Chile la conquista española encontró su límite por el Sur" (Navarro, 2004: $240)^{7}$. La resistencia mapuche al avance español fue heroica, gracias a una estrategia de mimesis, incorporando al caballo y diversas tácticas europeas. En 1598, el toqui Pelentraru, se alzó contra los peninsulares, destruyendo todas sus ciudades del Sur de Chile, en lo que se conoce como la victoria de Curalaba (Sierra, 1992).

Como dice Andrés Bello López: "Chile es el único de los pueblos modernos cuya fundación ha sido inmortalizada por un poema épico [La Araucana del español Alonso de Ercilla y Zúñiga, antes mencionada]" (Citado por Hamilton, 1974: 437). La estrategia de conquista, que le había resultado positiva a la Corona Española en casi toda América, "[e]n Chile y Argentina fue casi inaplicable durante cerca de tres siglos frente a los mapuches rebeldes del sur del paralelo 35. Porque para el mapuche, en cambio, esta guerra se sintetizaba en lo más concreto: defender la tierra hasta la muerte" (Hernández, 2001: 25-26). Opinión distinta plantea Villalobos, quien señala que la Guerra de Arauco, con posterioridad a 1598 se convirtió en una guerra de compenetración, con esporádicos choques militares (Villalobos, 1995). En este sentido, pienso que lo que conviene resaltar no es la existencia de una guerra continua e ininterrumpida por más de 300 años, sino el hecho de que Arauco nunca fue conquistado por el Imperio Español. Los españoles capitularon en el primer Parlamento de Quilín de 1641, reconocido el 29 de abril de 1643 por la Real Cédula de Felipe IV, reconociéndoles la soberanía efectiva a los araucanos en el segundo Parlamento de Quilín de 1647 (Contreras Painemal, 2010). Cabe agregar que los mapuches ya habían derrotado al Imperio Incásico (Barros Arana, 2000).

Hacia 1664 se computaban en más de treinta mil las bajas españolas, y sesenta mil indios auxiliares (yanaconas) que peleaban bajo la bandera española. En este sentido, Leyton Vidal señala que: "España nunca pudo someterlos [a los mapuches] y sus reyes reconocieron con verdadero pesar que la guerra de Arauco les costaba más que la conquista de todo el continente

En este sentido, Artola señala que: "Porque la verdadera frontera de guerra permanente del mismo, y por lo tanto las exigencias de la regularidad militar, estuvieron en el Arauco chileno". En Artola, 1988: 566. Al respecto, ver también: Zabala, J. M. (2000: 149).

8 Al respecto, ver Szászdi y Palma (1998: 699). 
de América" (Leyton Vidal, 1953: 37). A los españoles les resultó imposible "poner una pica en Arauco"9.

\section{Las lanzas de colihue}

Los mapuches usaban principalmente tres tipos de armas: las fechas, las picas (lanzas) y las mazas (macanas). En este sentido, Sierra señala que: "[P]ara los araucanos una lanza y una soga eran armas suficientes" (Sierra, 1992: 197). La lanza o pica, fabricada con madera de colihue:

"[e]ra terrible. Formábala una robusta quila (chusquea quila) hasta de cinco y seis metros de largo, cuya extremidad, cuidadosamente aguzada, penetraba en el cuerpo, casi como si estuviera provista de una punta de metal; y aun a veces, además, estaba armada de huesos o de piedras afiladas. Dirigida con singular maestría y con brazo vigoroso por el indio chileno, causaba heridas terribles y dolorosas $y$, con frecuencia, atravesaba al enemigo de parte a parte" (Barros Arana, 2000: 73-74).

Por otra parte, se debe indicar que la Guardia Real Española "[e]s una Unidad Militar de la Casa de Su Majestad el Rey. Es una de las unidades de estas características más antigua de Europa y es heredera de la Guardia de Alabarderos que, para la protección de Su Persona, creara don Fernando "el Católico» en 1504" (Casa de S. M. El Rey, 2004: 24). Los lanceros "[v]an armados con lanzas de coligüei, gramínea de la Patagonia, regalo de la República Argentina a los Regimientos de Lanceros en tiempos de don Alfonso XIII" (Mariani y Torres, 2004: 140).

\section{Cuestión final}

La historia es la testigo de la verdad, y dentro de ella se enmarca la hazaña de los mapuches, que son un fiel reflejo del carácter del pueblo chileno: abnegación, sacrificio y esfuerzo son su tríada. Su lucha fue por su libertad, a muerte. Valientes guerreros que siempre confiaron en la victoria y que nunca se dejaron dominar por su digno contrincante.

Esas lanzas empleadas por la Guardia Real Española significan ese sentimiento de entrega y valentía, bien lo saben los peninsulares, que entregaron el regalo del gobierno argentino a uno de sus cuerpos más nobles y honrosos.

9 En alusión al dicho "poner una pica en Flandes", que supone la dificultad en hacer alguna cosa. 
En el desfile del 12 de octubre de 2014, Día de la Hispanidad en España, en cada una de las lanzas que conformaban la Guardia Real -que escoltaban a don Felipe $\mathrm{VI}-$, vi a cada uno de los nombres mapuches, que ofrendaron su vida, sin miedo, por la libertad de su pueblo ${ }^{10}$, y sentí el homenaje que sus antiguos contrincantes (los naturales del Reino de España) le rendían.

Por último, la multiculturalidad de Chile es lo que le ha dado lustre a esta joven nación y en aquella aparecen los mapuches, unidos a elementos foráneos, que se amalgaman en el crisol de esta República. Me sorprende y complace el homenaje que España le rinde a los araucanos, pueblo nunca por ellos sometido.

\section{Referencias bibliográficas}

\section{Fuentes Primarias}

a) Documentales

Real Academia Española. (2001). Diccionario de la Lengua Española, vigésima segunda edición. Madrid: Impreso en Rotapapel.

\section{b) Impresos}

Ercilla y Zúñiga, A. de (1991). La Araucana. T. I. Edición de Marcos A. Morínico e Isaías Lerner. Madrid: Unigraf.

\section{Fuentes Secundarias}

\section{a) Artículos}

Hamilton, C. D. (1974). "Pablo Neruda, poeta chileno universal", en Cuadernos Hispanoamericanos. José Antonio Maravall (Direct.). № 287, mayo 1974. Madrid, pp. 437-441.

Mariani, S. y Torres, M. (2004). "Análisis químico cuantitativo y condiciones de pulpaje kraft de colihue: Parte I", en Bosque 25 (1). Valdivia: Instituto de Tecnología de Productos Forestales, Universidad Austral de Chile, pp. 117-122.

10 Las funciones de la Guardia Real están consignadas en el artículo $6^{\circ}$ del Real Decreto $n^{\circ}$ 434/1988, de 6 de mayo, sobre reestructuración de la Casa de S. M. el Rey, BOE n 112, de 10 de mayo de 1988. 
Szászdi León-Borja, I. y Palma González, E. E. (1998). "El Parlamento Hispano-Araucano de 1641: Naturaleza jurídica de un pacto internacional", en Libro homenaje In Memoriam de Carlos Díaz Rementería. Huelva: Universidad de Huelva, pp. 699-712.

\section{b) Libros}

Artola, M. (Direct.). (1988). Enciclopedia de Historia de España dirigida por Miguel Artola, II. Instituciones políticas. Imperio. Madrid: Alianza Editorial.

Barros Arana, D. (2000). Historia general de Chile. T. I, primera reimpresión. Santiago de Chile: Imprenta Salesianos.

Bengoa, J. (2000). Historia del pueblo mapuche. Siglo XIX y XX. Santiago de Chile: LOM Ediciones.

Bleiberg, G. (Direct.). (1968). Diccionario de Historia de España, segunda edición, corregida y aumentada, T. Primero. Madrid: Ediciones de la Revista de Occidente.

Casa de S. M. El Rey (2004). Enlace matrimonial de su Alteza Real el Príncipe de Asturias y Doña Leticia Ortiz Rocasolano. Madrid, 21 y 22 de mayo de 2004. Relaciones con los medios de comunicación, en sitio web: $<w w w$.casareal.es $>$.

Contreras Painemal, C. (2010). Los Tratados celebrados por los Mapuches con la Corona Española, la República de Chile y la República de Argentina. Berlín: Universidad-Prof. Dr. Jürgen Golte, Freie Universität Berlin.

Domeyko, I. (1971). Araucanía y sus habitantes. Buenos Aires: Editorial Francisco de Aguirre.

Faron, L. C. (1969). Los mapuche. Su estructura social, primera edición castellana. Ciudad de México: Instituto Indigenista Interamericano.

González García, P. (1995). Archivo General de Indias. Colección archivos europeos. Barcelona: Lunwerg Editores.

Hernández, I. (2001). Los mapuche. Derechos humanos y aborígenes. Buenos Aires: Galerna.

Leyton Vidal, C. (1953). Araucanía. Rostro de una raza altiva, segunda edición. Santiago de Chile: Gráfica Biancani.

Navarro, F. (Director). (2004). Historia universal, nº 14, América precolombina. Conquista de América. Formación de los imperios español e inglés. Madrid: Editorial Salvat. 
Neruda, P. (1962). Obras completas. Buenos Aires: Editorial Losada.

Olea Rosenbluth, C. (2010). La mujer en la sociedad mapuche: siglos XVI a XIX. Servicio Nacional de la Mujer. Santiago de Chile: Impresión LOM.

San Martín, S. (1997). Importancia de la cultura mapuche. Lo que la

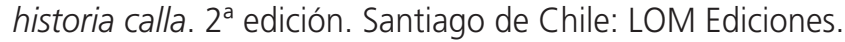

Sierra, M. (1992). Mapuche. Gente de la tierra. Santiago de Chile: Editorial Persona.

Villalobos, S. (1995). Vida fronteriza en la Araucanía. El mito de la Guerra de Arauco. Santiago de Chile: Editorial Andrés Bello.

Zabala, J. M. (2000). Les indiens mapuche du Chili. Dynamiques interethniques et stratégigies de résistance, XVIIIe siècle. Paris: Avant-propos de Pierre-Yves Jacopin, L'Harmattan.

\section{c) Sitios web}

Sitio web de la Universidad de Chile, visitado el día 25 de julio de 2016 [http://www.uchile.cl] 